\title{
Defined Observation Target Anatomic Site Laterality Code
}

National Cancer Institute

\section{Source}

National Cancer Institute. Defined Observation Target Anatomic Site Laterality Code. NCI Thesaurus. Code C93787.

A coded value specifying the side of the body (or a paired org an) that is a target site for an observation. 